\title{
Algumas vicissitudes do pensamento de Marx sobre a Rússia: a leitura de Karl Korsch ${ }^{1}$
}

Pedro Leão da Costa Neto²

Após a publicação de O Capital - e em particular na Rússia, após o aparecimento de sua tradução - abriu-se uma discussão sobre as possibilidades históricas de seu desenvolvimento. Essa discussão desenvolveu-se, fundamentalmente, a partir das observações desenvolvidas, em O Capital no capítulo dedicado à Acumulação Primitiva, tendo como indagação se o caminho lá esboçado teria uma validade universal. Em resposta a seus críticos, na sua carta de 1877 à redação de Otietchestviennie Zapiski, como também posteriormente na Carta e borrões em resposta à Carta de Vera Zasulitch, de $1881^{3}$, Marx restringe a validade das observações contidas naquele capítulo ao desenvolvimento do capitalismo na Europa Ocidental, e indica a possibilidade da Comuna Rural Russa oferecer uma alternativa de desenvolvimento histórico, que evitaria a necessidade de uma passagem pelo capitalismo.

Como sabemos, a publicação destes textos só ocorreu postumamente e foi acompanhada de uma verdadeira peripécia. Silenciada por Plekhanov, uma vez que seu conteúdo se chocaria com as posições defendidas pela Social-democracia russa a respeito do desenvolvimento do capitalismo na Rússia, o que

$-1-\cdots$

1 Esta comunicação, se inscreve dentro de um trabalho mais geral, de pesquisa sobre o Marx Tardío, e a sua recepção pela tradição marxista.

2 Professor de Filosofia na Universidade Tuiuti do Paraná. Doutor em Filosofia pela Universidade de Varsóvia. 3Karl Marx e Friedrich Engels, Escritos sobre Rússia II: El Porvenir de la Comuna Rural Rusa. México, Siglo XXI, 1980.

cadernos cemarx, $n^{0} 2-2005 / 79$ 
atrapalharia no combate aos populistas. Esta correspondência só será publicada posteriormente .

Dos diferentes comentaristas destas cartas, particularmente interessantes, são os comentários de Korsch a estes textos. As constantes referências a estas cartas - em particular a de 1877 -, bem como ao conteúdo nelas presentes, são indicativas da importância que o autor atribuía a elas. As primeiras observações aos referidos textos já aparecem em Marxismo e Filosofia (1923), e no seu Kernpunkte (1922), onde a Carta à Redação de Otietchestviennie Zapiski aparece como apêndice.

Entretanto seria ao longo década de 30 , que Korsch voltaria inúmeras vezes aos referidos textos, como exemplo de um dos pontos essenciais do marxismo, ou seja do caráter específico das suas proposições.

No capítulo 3: Aplicação específica da Parte III: História, do seu livro Karl Marx, (1938), referindo-se a "leis de desenvolvimento que governam a passagem de uma formação social a outra", nos remete em uma nota de pé de página: "a carta de Marx, do final de 1877, à redação de Otiéchestviennie Zapiski, que em resposta a um artigo do sociólogo russo Mikhailovski, ilustra o específico caráter histórico da exposição no final do livro I de O Capital, da acumulação primitiva e da geral "tendência histórica da acumulação capitalista" que daí deriva."

Nesta mesma nota, Korsch nos remete ao seu Anti-Kautsky, (1929), onde afirma:

é suficiente acenar as numerosas declarações com as quais Marx se é expressamente recusado de formular leis de qualquer gênero e seja mesmo leis "universais" de caráter meta-histórico. ${ }^{6}$

Na introdução a sua edição de O Capital (1932), Korsch afirma que Marx:

(...) não pretendia nem remotamente converter seu novo princípio em uma

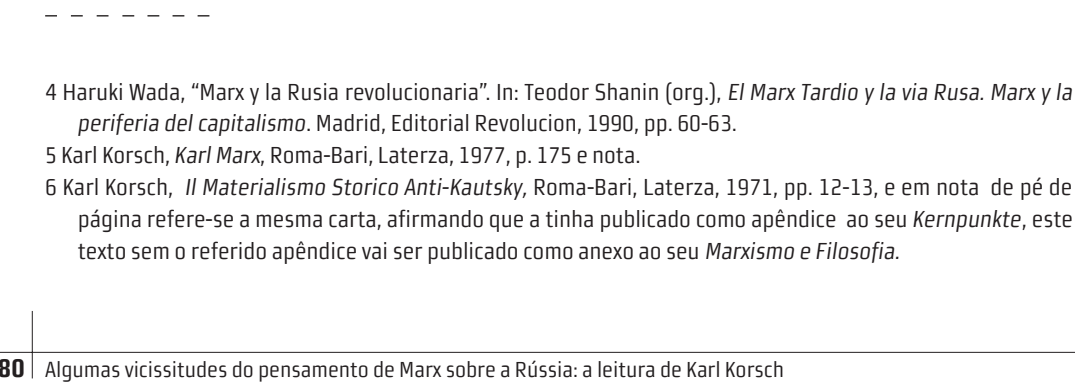

80 Algumas vicissitudes do pensamento de Marx sobre a Rússia: a leitura de Karl Korsch 
teoria filosófica geral da história, que seria imposta desde o exterior sobre o padrão atual dos acontecimentos históricos. (...) Faz cinqüenta Marx rechaçou algumas concepções errôneas sobre o método de O Capital, mantidas pelo sociólogo e idealista russo Mikhailovski, explicando que O Capital, em particular as conclusões a qual chegou na Secção Sétima sobre a acumulação primitiva, não pretendia ser nada mais que uma descrição histórica das origens e do desenvolvimento do capitalismo na Europa Ocidental. ${ }^{7}$

O mesmo Korsch, em seu escrito Por Qué Soy Marxista, (1935), retoma estas mesmas observações e acrescenta:

De fato, este meu argumento só repete e acentua um princípio que o mesmo Marx expressou explicitamente faz cinqüenta anos ao corrigir o sociólogo idealista russo, Mikhailovski, em sua interpretação errônea do método de O Capital.

Certamente, constitui uma necessária implicação do princípio fundamental da pesquisa empírica que em nossos dias é somente negado por alguns metafísicos inveterados. (...) O princípio da dialética materialista, tal como está encarnado na economia marxiana, não significa outra coisa que a relação específica de todos os termos e proposições econômicas com os objetos historicamente determinados. ${ }^{8}$

Podemos portanto depreender das passagens citadas, a importância atribuída por Korsch, a esta correspondência, em particular no tocante à questão do caráter específico das afirmações marxistas, assim como de uma crítica a toda tentativa de transformar o marxismo em uma teoria da história. Esta concepção, como podemos depreender a partir da argumentação korschiana está associada a sua concepção de que o materialismo histórico se aplicaria somente ao Modo de Produção capitalista ${ }^{9}$, bem como à suas críticas às concepções "das frações russas e alemães do marxismo ortodoxo."10

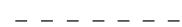

7 Karl Korsch, Introducción a El Capital (1932), In: Tres ensayos sobre marxismo, México: Ediciones Era, 1979, pp. 79-80.

8K. Korsch, Por Qué Soy Marxista, Idem, pp.87-88.

9 K. Korsch, Karl Marx, op. cit., p. 175.

10 K. Korsch, Por Qué Soy Marxista, op. cit, p. 87. Cf., também a crítica a crítica a Kautsky citada na nota 5.

cadernos cemarx, $\mathrm{n}^{0} 2-2005 \mid \mathbf{8 1}$ 
Entretanto, em outros escritos da mesma década de 30, dedicados à questão da recepção do marxismo na Rússia, as suas observações sofrerão uma mudança significativa, fazendo observações que se distanciarão das que acabamos de reproduzir. Korsch, em seu escrito Sobre a história da ideologia marxista na Rússia (1932 e 1938), pretende analisar o desenvolvimento do marxismo na Rússia a partir do princípio crítico materialista do marxismo, e assim revelar "a contradição entre entre a ideologia marxista, por um lado, e, por outro, o movimento histórico real. que foi ocultando-se sob este revestimento ideológico"11. Refere-se primeiramente, às necessidades de modificações no conteúdo teórico-ideológico do marxismo original, para adaptar-se à realidade russa, das últimas décadas do século XIX. Korsch após reproduzir as palavras de Marx e Engels, escritas para o Prefácio a segunda edição do Manifesto Comunista na Rússia, no qual os autores afirmam que a Revolução Russa pode servir de sinal para a Revolução européia e, dessa maneira a comuna rural russa poderia servir como ponto de partida para transformações comunistas, afirma ainda:

Nestas frases de Marx e em numerosas expressões semelhantes de Marx e Engels, que encontramos no mesmo período em sua correspondência, em particular nas cartas ao teórico populista russo Nikolaion, na carta a Vera Zassulich e na resposta a Mikhailovski, vem já antecipando em um certo sentido todo o posterior desenvolvimento do marxismo russo e sobretudo à contradição que cada vez mais se abriu entre a ideologia e o real conteúdo histórico deste desenvolvimento. ${ }^{12}$

E acrescenta:

Também Marx e Engels, estavam dispostos, em certas condições, a transformar sua teoria crítico- materialista "marxista" a favor de um movimento revolucionário no Oriente com modificações oportunas no mero disfarce ideológico de um movimento revolucionário presumidamente socialista, porém na sua substância real limitado no sentido burguês. Se inicia assim essa característica mudança histórica de fun-

$---{ }_{--1}$

11Karl Korsch, “Sobre a história da ideologia marxista na Rússia”. In: Teoria Marxista y Acción Política, México: Cuadernos de Pasado y Presente no 84, p. 180.

12 Idem, p. 182.

82 Algumas vicissitudes do pensamento de Marx sobre a Rússia: a leitura de Karl Korsch 
ção, pelo qual o marxismo "recebido" pelos revolucionários russos se transformou no sucessivo desenvolvimento de expressão teórica de um movimento revolucionário proletário socialista em ideologia "socialista" de um movimento de construção burguesa capitalista. Se inicia também a metamorfose teórica (...) a partir da época dos mesmos Marx e Engels e com a sua consciente e ativa colaboração. Com as suas concessões ao populismo revolucionário eles queriam permitir a temporária re-elaboração de sua teoria "marxista" em um mito revolucionário..."13

Korsch, ao se referir aqui ao "mito", está nos remetendo à leitura de Marx efetuada por G. Sorel, na qual afirmava que a concepção marxista de uma tendência geral do capitalismo rumo a catástrofe provocada por uma insurreição proletária, deve ser classificada puramente como um "mito". ${ }^{14}$ Korsch estendeu igualmente esta concepção de Sorel para a análise das crises do capitalismo, como também afirmaria que a crítica de Lenin aos populistas está baseada em um "mito."

Depois de deter-se nos vários aspectos da leitura de Marx feita por Korsch, a comunicação retornará por fim, a analisar se esta mudança de concepção do autor de Marxismo e Filosofia, está, por um lado, associada à sua compreensão teórica do Marxismo, como uma teoria aplicável somente a sociedade capitalista e por outro lado, com as suas posições, cada vez mais críticas, sobre a evolução social na Rússia.

13 Idem, pp. 182-183.

14 Karl Korsch, "Sobre algunos presupuestos básicos para una discussion materialista de la teoría de las crisis (1933)". In: K. Korsch, Sobre la Teoria y la Practica de los Marxistas, Salamanca: Ediciones Sígueme, 1979, p. 200 (Esta coletânea reproduz em grande parte, os mesmos artigos que foram reunidos na coletânea citada na nota 4).

15 Karl Korsch, "El Marxismo y las tarefas actuales en la lucha de classes proletaria (1938)", Idem, pp. 233-234 e pp. 200-ट01.

cadernos cemarx, $n^{0} 2-2005 \quad \mathbf{8 3}$ 